\title{
Existe uma Parte "Anômala" da Curva de Laffer?"
}

\author{
Walter E. Block
}

Resumo: $\mathrm{O}$ autor discute neste artigo as implicações do Princípio da Não Agressão (PNA) do libertarianismo à luz de exemplos hipotéticos e mostra que tal princípio não é universal e nem fácil de analisar e aplicar.

Palavras-chave: Curva de Laffer, Libertarianismo, Imperativo Categórico, Imperativo Hipotético.

\section{Is There an "Anomalous" Section of the Laffer Curve?}

\begin{abstract}
The author discusses the implications of the libertarian non-aggression principle (NAP) in the light of hypothetical examples and shows that this principle is not universal and not easy to analyze and apply.
\end{abstract}

Keywords: Laffer curve, Libertarianism, Categorical Imperative, Hypothetical Imperative.

Classificação JEL: B41, D81, Z0

\footnotetext{
*Artigo publicado originalmente em inglês em: Libertarian Papers, v. 2, art. n. 6, 2010.

Traduzido do inglês para o português por Vítor Pimentel Pereira.

${ }^{* *}$ Walter Block nasceu em 21 de agosto de 1941, no Brooklyn, em New York, nos Estados Unidos. É professor de Economia da Loyola University, em New Orleans, na Lousiana, e Senior Fellow do Ludwig von Mises Institute. Cursou a licenciatura em Filosofia no Brooklyn College e o PhD em Economia na Columbia University. É autor de mais de quinhentos artigos publicados em diferentes jornais, revistas ou periódicos acadêmicos, além de ser autor, co-autor e organizador de inúmeros livros, dentre os quais o seguinte foi publicado em língua portuguesa: Defendendo o Indefensável (Instituto Ludwig von Mises Brasil, 2010).

E-mail: wblock@loyno.edu
} 
Suponhamos que estamos na parte descendente da curva de Laffer. Isso significa que, a alíquota tributária é diminuída e maiores receitas tributárias reverterão para o governo ${ }^{1}$. Digamos que o Estado é uma instituição má; afinal, essa é uma análise libertária. Assim, chegamos àquilo que deve contar, para dizer o mínimo, como uma anomalia. Uma redução na alíquota tributária é usualmente vista como um fenômeno pró-liberdade. E aqui, claro, o PIB crescerá. Todos ficaremos mais ricos. A deontologia, ao menos a partir de uma perspectiva libertária, juntamente com considerações utilitaristas de maximização da riqueza, falam em uníssono diante de tal panorama: isso é uma coisa boa desde ambas as perspectivas. Contudo, e isso é uma grande exceção, a partir do ponto de vista libertário, os cofres governamentais também vão ser reforçados, e isto é uma coisa ruim.

Não devemos ficar muito entusiasmados com isso, ao menos ainda não. Esse não é o primeiro caso registrado em que algo de positivo desde a perspectiva libertária é acompanhado por um resultado que somente pode ser visto como negativo. Por exemplo, se drogas que causam dependência fossem legalizadas, e colocadas em pé de igualdade com o álcool, o governo poderia tributar esses produtos. A legalização das drogas é, certamente, um passo em direção da liberdade, mas um aumento da riqueza estatal certamente não o é .

Então, nesses dois casos, o da curva de Laffer $^{3}$ e o da legalização das drogas, temos exceções à regra geral de que o utilitarismo,

\footnotetext{
${ }^{1}$ Bem como para os cidadãos, é claro.

2 Ouvimos supostos libertários apoiarem a descriminalização de substâncias que causam dependência com base na ideia de que as receitas fiscais seriam, assim, aumentadas. Tal postura é, sem dúvida, incompatível com essa filosofia. Em outras palavras, o fato de que mais receitas reverterão a favor do Estado é um argumento contra a legalização das drogas.

${ }^{3}$ Para uma análise diferente, mas não incompatível, da curva de Laffer, ver: BARNETT, William II \& BLOCK, Walter. On the Use and Misuse of the Laffer Curve. Journal of Public Finance and Public Choice, v. 24, n. 3, p. 139-52. 2005
}

em uma interpretação ampla, e o libertarianismo sempre trabalham na mesma direção. Aqui, a diminuição das alíquotas tributárias e a legalização das drogas, embora indubitavelmente reforcem a riqueza, a liberdade e a prosperidade ${ }^{4}$, são também acompanhadas por redução do bem-estar: o Estado tem mais meios com os quais pode ampliar o escopo de suas depredações.

Tudo bem, por enquanto. Provavelmente, nenhum libertário discordaria do anteriormente dito; mas será que há algo mais nessa questão que uma mera anomalia? Estamos diante de um caso que nos leva a questionar, nestas circunstâncias, se os libertários deveriam dar seu apoio integral e incondicional para baixar as alíquotas tributárias (e para descriminalizar as drogas)? Afirmo que até mesmo abordar esta questão leva-nos a complicados cipoais ${ }^{5}$.

Antes de prosseguir com esta linha de investigação, vamos colocar mais um caso sobre a mesa: o alistamento militar compulsório levado a cabo durante a Guerra do Vietnã. Aqui, postulo que a participação dos EUA nessa conflagração foi injusta. Nosso governo lutou contra um país a dez mil milhas de distância de nossas costas, um país que não representava perigo algum de invadir-nos. Essa foi uma guerra imperialista, pura e simplesmente. Supomos ainda que, caso houvesse um serviço militar voluntário à época, os EUA teriam sido capazes de prosseguir com o assassinato dessas vítimas estrangeiras inocentes por uma duração mais longa, e em grau muito superior ao que efetivamente foi realizado. ${ }^{6}$ Assim, o alistamento compulsório

\footnotetext{
${ }^{4}$ A parte da renda que efetivamente fica com os contribuintes aumenta e as pessoas não são mais brutalizadas por inserir substâncias químicas em seus próprios corpos. Adultos que consintam entre si não serão mais presos por comprar e vender tais substâncias.

${ }^{5} \mathrm{Eu}$ lhes disse que as coisas ficariam mais "interessantes".

${ }^{6}$ Para um argumento em favor do serviço militar voluntário com base na ideia de que essa política de força de trabalho permite ao governo, mais eficazmente, levar adiante guerras que os libertários consideram injustas, ver: BOUDREAUX, Donald. A Life-Saving
} 
salvou vidas ao acabar com essa guerra injusta mais cedo do que teria sido o caso se se procedesse de outra forma ${ }^{7}$.

Temos na balança, aqui, a interferência com a conveniência de toda uma coorte etária de cidadãos norte-americanos que foram alistados compulsoriamente, e, sim, as mortes de mais do que alguns deles ${ }^{8}$, contra o assassinato em grande escala de vietnamitas inocentes, tanto no Norte como no Sul'.

O que todos estes três casos têm em comum é uma política claramente libertária ${ }^{10}$ que foi acompanhada, em uma relação de causa e efeito, por resultados antilibertários ${ }^{11}$. Em razão disso, deveriam os libertários opor-se a essas três iniciativas? Especificamente, devemos, enquanto libertários, resistir a alíquotas tributárias mais baixas quando estivermos localizados na parte descendente da curva de Laffer? Será que nós, adeptos do capitalismo laissez faire, devemos contestar a legalização das drogas com fundamento no fato de que a legalização vai robustecer a riqueza do go-

Lesson from Operation Desert Storm. The Freeman, v. 43, n. 10. October 1993. Este autor, que não é libertário, opôs-se de fato ao alistamento militar obrigatório exatamente em razão disso. Para uma crítica deste ponto de vista, ver: BLOCK, Walter E. Against the Volunteer Military. The Libertarian Forum, n. 15, p. 4. August 1969.

${ }^{7}$ Quando os graduados das principais faculdades norteamericanas [Ivy League] foram forçados a assumir os encargos e os riscos da batalha, tal fato foi o golpe de misericórdia para o envolvimento dos EUA no Vietnã.

${ }^{8}$ Em verdade, cerca de 50.000 deles (<http://thewallusa.com/summary.asp $>$; <www.vhfen.org/stat.htm $>$ ).

${ }^{9}$ As estimativas (<http://answers.google.com/answers/ threadview?id=5096>) melhores são de cerca de 4 milhões de civis, e mais de 1 milhão de militares, e isso não inclui as mortes no Laos e no Camboja também devidas ao imperialismo dos EUA. Muito mais vietnamitas que soldados norte-americanos morreram, provavelmente devido às vantagens tecnológicas desfrutadas por estes últimos.

${ }^{10}$ Alíquotas tributárias mais baixas, drogas legalizadas e o fim do alistamento militar obrigatório.

11 O governo ampliou o financiamento com o qual prosseguirá seus atos malignos, incluindo-se aí levar a cabo guerras injustas. verno, e assim permitir que este continue a perpetrar ações ainda mais malignas do que no presente? Deve o movimento da liberdade - será que dá para imaginar isso?, na verdade, estar a favor de um alistamento militar compulsório?

"Nem pensar nisso", seria a resposta típica que emanaria dos libertários. E, de fato, tais posições parecem verdadeiramente um contrassenso desvairado. No entanto, vamos tentar fazer pender a balança na direção das considerações utilitaristas, e para longe do que parecem, pelo menos inicialmente, ser as respostas corretas para essas questões deontológicas.

Suponhamos que, se qualquer uma dessas três políticas libertárias fossem executadas, os todo-poderosos marcianos explodissem toda a Terra e tudo sobre ela perecesse. Por quê? Porque o governo dos EUA teve as seguintes vantagens: a receita adicional espoliada dos contribuintes - sofredores de longa data - devido a uma queda na alíquota tributária, o dinheiro suplementar advindo ao governo a partir da legalização das drogas, além de um serviço militar voluntário que não suscitou protestos contra sua instituição. Com esses benefícios, o governo dos EUA, como era de costume, atacou Marte, podemos agora supor. Sem essas receitas adicionais, os Estados Unidos teriam sido obrigados a seguir uma política de paz com o quarto planeta. Sem que as autoridades norte-americanas soubessem, em vez de atormentar países relativamente indefesos, em Marte, encontraram mais do que poderiam suportar.

Diante desse quadro, acaso as alíquotas tributárias menores, etc., chegam mesmo a ser compatíveis com o libertarianismo, ou melhor, será que chegam a ser, sob tais condições, exigências dessa filosofia?

É o momento de refletir sobre a filosofia da liberdade em mais detalhes. À primeira vista, o libertarianismo pode ser definido como a personificação do axioma de não agressão juntamente com a teoria da aquisição original dos direitos de propriedade (Rothbard, 1973, 1998). Aqui, o libertarianismo excluiria os tri- 
butos mais elevados, a proibição das drogas e o alistamento militar obrigatório. Todos violam o Princípio de Não Agressão (doravante, PNA). É minha opinião, no entanto, que, apesar de essa definição ser suficiente para a esmagadora maioria dos casos "normais", é apenas uma primeira aproximação à verdade. Deixa a nossa amada filosofia vulnerável ao exemplo marciano. "Faça-se a justiça, ainda que pereça o mundo" (ou que a Terra seja destruída), não pode e não deve ser tudo o que há de relevante para o libertarianismo.

Proponho, portanto, uma alternativa, ou melhor, uma explicação adicional do libertarianismo. Nesta visão, o libertarianismo torna-se uma teoria da pena, em seu formato mais bem desenvolvido. Punição para quê? Para a violação do PNA, é claro!

Devemos nos apegar a alguns vestígios do libertarianismo tradicional nesse novo entendimento. Na ordenação alternativa, o libertário na verdade diria ao candidato a assassino ou estuprador: é uma questão irrelevante para nós se vocês irão ou não se envolver nos atos que agora estão planejando. Enquanto libertários, realmente não nos importamos se agirão de uma forma ou de outra ${ }^{12}$. No entanto, se vocês se envolverem em tais atos, nós vamos puni-los com todo o rigor da lei ${ }^{13}$.

12 Enquanto promotores da ética, obviamente nos opomos ao homicídio, estupro e outras formas indesejadas de cruzar as fronteiras éticas.

${ }^{13}$ A teoria libertária da punição demanda medidas um tanto quanto draconianas. Sobre isso, ver: BLOCK, Walter E. Market Inalienability Once Again: Reply to Radin, Thomas Jefferson Law Journal, v. 22, n. 1. p. 37-88. Fall 1999; Idem. Berman on Blackmail: Taking Motives Fervently. Florida State University Business Review, v. 3, n. 1, p. 57-114. 2002-2003; Idem. Libertarianism vs. Objectivism; A Response to Peter Schwartz. Reason Papers, v. 26, p. 39-62. Summer 2003; Idem. Austrian Law and Economics: The Contributions of Adolf Reinach and Murray Rothbard. Quarterly Journal of Austrian Economics, v. 7, n. 4, p. 69-85. Winter 2004; Idem. Reply to Frank van Dun's 'Natural Law and the Jurisprudence of Freedom', Journal of Libertarian Studies. v. 18, n. 2, , p. 65-72. Spring 2004; Idem. Radical Libertarianism: Applying Libertarian Principles to Dealing with the Unjust Government, Part II, Reason Papers, v. 28, p. 85-109. Spring 2006;
Há dois problemas que devem ser abordados que surgem imediatamente com esta interpretação. Em primeiro lugar, é realmente verdade que é uma questão irrelevante se o PNA é ou não violado? Bem, de acordo com o velho ditado, "Não fique furioso; dê o troco!", há de fato um sentido em que nós realmente não nos "importamos". Todo "cuidado" do mundo, enfim, não irá proteger contra violações do PNA. Como moralistas, ainda podemos investir contra esses atos covardes; mas se realmente quisermos impedir as pessoas que não podem ser dissuadidas desses atos por considerações de comportamento civilizado, apenas uma ameaça crível de força, efetivamente realizada com alta probabilidade, será suficiente. Quando confron-

Idem. Libertarian Punishment Theory: Working for, and Donating to the State. Libertarian Papers, v. 1, art. n. 17, 2009; Idem. Toward a Libertarian Theory of Guilt and Punishment for the Crime of Statism, Journal of Libertarian Studies, v. 22, p. 665-75. 2011; BLOCK, Walter ; BARNETT II, William \& CALLAHAN, Gene. The Paradox of Coase as a Defender of Free Markets. NYU Journal of Law \& Liberty, v. 1, n. 3, p. 107595. 2005; GREGORY, Anthony \& BLOCK, Walter. On Immigration: Reply to Hoppe. Journal of Libertarian Studies, v. 21, n. 3, p. 25-42. Fall 2007; OLSON, Charles B. "Law in Anarchy." Libertarian Forum. Vol. XII, No. 6, p. 4. November-December, 1979; ROTHBARD, Murray N. A Ética da Liberdade. Intr. Hans-Hermann Hoppe; Trad. Fernando Fiori Chiocca. São Paulo: Instituto Ludwig von Mises Brasil, 2a Ed. 2010; WHITEHEAD, Roy \& BLOCK, Walter. Taking the assets of the criminal to compensate victims of violence: a legal and philosophical approach. Wayne State University Law School Journal of Law in Society, v. 5, n. 1, p. 229-54. Fall 2003. Na visão de Murray N. Rothbard (1926-1995): "Deve ficar claro que a nossa teoria de punição proporcional - que as pessoas podem ser punidas perdendo seus direitos na mesma extensão em que eles invadiram os direitos de outros - é francamente uma teoria retaliativa de punição, uma teoria de 'dente (ou dois dentes) por dente'. A retaliação tem uma má reputação entre os filósofos, que geralmente descartam o conceito rapidamente por ser algo 'primitivo' ou 'bárbaro' e desviam rapidamente a discussão para as outras duas maiores teorias de punição: dissuasão e reabilitação. Porém, não é muito adequado descartar um conceito simplesmente chamando-o de 'bárbaro'; afinal, é possível que, neste caso, os 'bárbaros' tenham chegado a um conceito superior à maioria das crenças modernas" (ROTHBARD. A Ética da Liberdade. p. 152). 
tamos a situação, isso é realmente tudo que, de qualquer maneira, a sociedade pode empregar contra os saqueadores. Segundo, será que tal interpretação fortalece o PNA, ou vai de encontro a ele? Minha posição é a de que não somente essa interpretação embasará o PNA, mas também que é a melhor maneira de fazê-lo. Não consigo pensar em uma maneira melhor de promover a obediência ao PNA que ameaçar com sanções físicas aqueles que a violam.

Aqui, então, está o desenlace. $\mathrm{O}$ governo está pensando em baixar as alíquotas tributárias. Nós libertários sabemos (determinamos) que, se o fizer, ganhará recursos adicionais necessários para provocar os marcianos, os quais vão acabar com tudo para todos nós ${ }^{14}$. Assim, os libertários de alguma forma derrubam essa redução da alíquota tributária, salvando assim o planeta da destruição ${ }^{15}$. É claro, no entanto, que esses libertários responsáveis pela revogação da redução dos tributos $^{16}$ são culpados de um crime. Com efeito, roubaram a receita adicional que teria beneficiado os contribuintes - sofredores de longa data - sob a égide do plano de redução de alíquotas tributárias. Então, devem ser punidos por violar o PNA. Primeiro, realizamos uma parada com chuva de papel picado para esses criminosos $^{17}$, festejando-os ao redor de todo o (agradecido) mundo (já que que salvaram a humanidade). Foram realmente heróis, uma vez que não só nos salvaram, mas, enquanto libertários, agiram contra o querido PNA. Mas, então, dada a nossa nova interpretação do libertarianismo, nós iremos puni-los com

\footnotetext{
${ }^{14} \mathrm{Se}$ fossem apenas os homens brancos entre nós, isso seria tolerável; mas mulheres, negros, homossexuais e outros grupos vitimados protegidos também seriam abatidos, e isso nenhuma ordem civilizada, decente e politicamente correta poderia tolerar.

${ }^{15}$ Os Verdes, pelo menos, nos apoiariam neste ponto. Podem não se preocupar muito com a humanidade, mas eles adoram a Gaia Terra.

${ }^{16}$ Pense em um "político" no estilo Ron Paul.

17 Sem aspas de espanto em torno desta palavra ["criminosos"]. Estes libertários são, de fato, criminosos; eles violaram o PNA.
}

todo o rigor da lei, e com a sua aquiescência! ${ }^{18}$ Eles sabiam muito bem o que estavam fazendo quando se recusaram a baixar as alíquotas tributárias, ou se recusaram a legalizar as drogas, ou quando organizaram um alistamento militar obrigatório, tudo para manter os marcianos longe de nosso encalço. Estavam salvando a raça humana violando o PNA. Assim, enquanto bons libertários, que também são utilitaristas, acolhem a sua punição. Assim, mas somente assim, podemos comer a nossa fatia de bolo utilitarista e manter também a nossa fatia de bolo deontológica.

Contudo, há uma mosca na sopa. Os marcianos, tipos inteligentes, como seres diabólicos que são, estão determinados a que nós, terráqueos libertários, não possamos ter o nosso bolo e comê-lo também. Não querem nos permitir salvar a Terra e manter ao mesmo tempo o nosso PNA. Ou, ao menos, punir aqueles que o violam. Então, enviam a seguinte mensagem: "se vocês punirem os heroicos libertários que estavam tentando salvar o planeta e seu PNA ao mesmo tempo, proibindo as drogas, ou instituindo o alistamento militar obrigatório, ou opondo-se às reduções das alíquotas tributárias, se vocês sequer tocarem em um fio de cabelo de suas cabeças, vamos renovar nossa ameaça irreversível de matar a todos vocês." Bem, isso é demais até mesmo para o autor deste texto. Se os marcianos, armados com seu poder irresistível, estão dispostos a ir tão longe, não podemos manter o nosso PNA e salvar o mundo da extinção ${ }^{19}$.

Claro, se os marcianos estão tão determinados a ponto de forçar um abismo entre o utilitarismo e a deontologia libertária, nós, meros mortais, não podemos detê-los. Então, o que ganhamos ao interpretar o PNA libertário como sendo apenas a primeira aproxi-

\footnotetext{
${ }^{18}$ Ainda reverenciam o PNA, mesmo quando o violam. Acolhem a sua punição.

${ }^{19}$ Embora tenhamos aparentemente comprometido o PNA neste artigo, ainda sou radical o suficiente para dizer aos marcianos neste momento que "vão pastar", "que me importa o que vocês farão?", etc. O adágio "Faça-se a justiça, ainda que pereça o mundo" pode ser adiado, por enquanto.
} 
mação do libertarianismo e ao chamar a teoria libertária da punição uma versão mais sofisticada e mais verdadeira da nossa filosofia? Demos um passo importante na discussão. Enquanto nós libertários "meramente" tínhamos de instituir um alistamento militar obrigatório, aumentar as alíquotas tributárias e / ou rejeitar a legalização das drogas, nossa reconciliação era possível. Poderíamos nos apegar à nossa versão de libertarianismo baseada na teoria da punição, enquanto o velho e bom PNA simplista certamente não podia. Foi apenas quando os marcianos (malandros inteligentes) moveram sua pesada artilharia intelectual e que fomos forçados a retirarmo-nos do campo de batalha em desordem, obrigados a concordar com a destruição de todo o terceiro planeta [a Terra], ou renunciar à interpretação do libertarianismo como uma teoria da punição.

Vamos tentar tornar esse ponto mais claro de uma outra maneira. No filme $D r$. Strangelove [Dr. Fantástico] ${ }^{20}$ de Stanley Kubrick (1928-1999), há uma cena em que as personagens precisam de troco em moedas para usar em um telefone público operado por moedas. A ligação é muito importante; irá, remontando ao exemplo dos marcianos, salvar o mundo da destruição nuclear. O problema é que nenhuma das personagens tem sequer uma moeda. No entanto, há uma máquina de Coca-Cola parada ali, abarrotada de moedas. Uma personagem aponta para a máquina e diz a um soldado com uma arma para atirar nela, de modo que possam valer-se dos meios necessários para fazer a chamada de telefone vital. Horrorizada, outra personagem diz, balbuciando: "Mas você não pode fazer isso. Essa máquina de Coca-Cola é propriedade privada (paráfrase)". A frase angaria, talvez, a maior gargalhada de todo o filme. É um ataque direto ao PNA. Pensemos, por um momento, nos imperativos categórico e hipotético de Immanuel Kant (1724-1804). O PNA assume a posição do primeiro. Afirma, com efeito, "Não invadirás as máquinas de

${ }^{20}$ Ver: www.imdb.com/title/tt0057012/
Coca-Cola para obter moedas, não importando se o destino de todo o mundo está em jogo." Se essa é a essência do libertarianismo, então é suscetível a exatamente esse tipo de objeção. E essa é verdadeiramente uma objeção poderosa, como testemunha, durante a cena, o sentido do riso de cada espectador que já viu este filme.

Por outro lado, o imperativo hipotético kantiano declararia o seguinte: "Se você quebrar a proverbial máquina de Coca-Cola - sua pessoa podre e imoral! -, então você terá de pagar perdas e danos muito graves pela sua destruição de propriedade privada." Minha afirmação é a de que essa é uma postura muito mais palatável para a filosofia do libertarianismo abraçar. Para concluir esta seção do artigo. O PNA, simpliciter [em sentido estrito], implica que nunca, jamais devemos nos opor à legalização das drogas, não importa quais as consequências. A versão mais sofisticada do libertarianismo, a teoria da punição, afirma algo muito diferente. Se as consequências são grandes o suficiente em termos de violações de direitos, então, de fato, é apropriado para um libertário se opor à legalização das drogas, desde que aqueles que se opõem a ela paguem a pena adequada. Idem para baixar as alíquotas tributárias, supondo a nossa localização na parte descendente da Curva de Laffer. Se isso vai conceder ao maligno governo meios suficientes para a prática de suficientemente graves violações de direitos, então heróis libertários devem se opor, mas devem estar dispostos e prontos para pagar a pena por cooperar com o roubo. E, sim, mesmo o alistamento militar obrigatório se justifica se as consequências do serviço militar voluntário são terríveis o suficiente.

Vamos agora considerar vários outros casos, de modo a esclarecer este ponto de vista. Estritamente falando, empurrar alguém para fora do caminho de um caminhão em movimento que irá matá-lo se ele permanecer onde está agora constitui agressão e lesão corporal. Se alguém desejar ser heroico o suficiente para fazer isso, 
deve estar disposto a (possivelmente) pagar a pena por fazê-lo ${ }^{21}$. Se o salvador empurra com bastante força, a pessoa salva pode ter o braço quebrado. Pode parecer grosseiro por parte da pessoa processar o salvador pedindo perdas e danos, mas isso seria seu direito sob a égide da interpretação atual do libertarianismo.

Investiguemos um pouco mais essa difícil questão. Na estreita, limitada, restrita - ousamos dizer, simplista - interpretação do PNA, é ilícito e impróprio violar o PNA, ponto final. Sem exceções. Qualquer um que o fizer, ou defender que isso seja feito, não é, nessa medida, um libertário. Em termos kantianos, temos um imperativo categórico: não se pode violar o PNA, caso encerrado.

Por outro lado, a nossa ampla, livre, aberta e complexa interpretação é a de que o PNA é a estrela polar do libertarianismo. No entanto, na minha opinião, às vezes é legítimo violar o PNA; porém, caso seja violado, a pessoa que o faz está obrigada a assumir o castigo por agir assim. Em termos kantianos, interpretamos o PNA como um imperativo hipotético e não categórico.

Nossa alegação é a de que a outra perspectiva não só não pode lidar com casos descontrolados como os dos repugnantes marcianos e o dos tiros às máquinas de Coca-Cola do Dr. Strangelove, mas também falha em toda uma série de outros exemplos. Consideremos o seguinte.

A está se afogando. Estipulo que A vai morrer em breve. B pode salvá-lo; mas, se B o faz, estará cometendo agressão e lesão corporal contra A. Suponhamos que A lute durante os esforços de B para salvá-lo, sendo o único caminho para B salvá-lo que este golpeie A, deixando-o inconsciente. Segundo o outro ponto de vista, $B$ não pode fazer isso. É incompatível com o libertarianismo do PNA. Na minha opinião, B pode fazer isso, mas então está obrigado a pagar

\footnotetext{
${ }^{21}$ Não podemos negar que algumas pessoas atuarão heroicamente dessa maneira, mas somente se não enfrentarem qualquer eventual repercussão jurídica.
}

a A pelo dano e violação de direitos que cometeu contra ele ${ }^{22}$.

Outro caso: C está prestes a cometer suicídio, pulando de uma ponte. $\mathrm{D}$ vê isso e agarra $\mathrm{C}$ em um abraço bem apertado, arrastando-o para longe da ponte, e tenta convencê-lo a não tirar a própria vida. $\mathrm{D}$ mantém $\mathrm{C}$ cativo por um dia, e decorrido esse prazo permite a $C$ fazer com a sua vida exatamente o que quiser. Nesse meio tempo, no entanto, D é culpado de cárcere privado, sequestro, lesão corporal. Na visão libertária tradicional, seria impróprio fazer isso. Ele violou o PNA, e isso foi antilibertário. Na minha perspectiva, isso certamente violou o PNA, mas, desde que D estivesse disposto a sofrer a penalidade por sua violação do PNA, suas ações foram compatíveis com o libertarianismo; até mesmo heróicas.

Um terceiro caso. A visão simplista é compatível com a de Murray N. Rothbard (1926-1995) sobre John C. Calhoun (17821850) ${ }^{23}$; os consumidores de tributos [os que recebem dos cofres públicos] são os maus, os contribuintes de tributos [os que pagam ao governo] são as vítimas. Ponto final. $\mathrm{Na}$ minha compreensão, por outro lado, essa é apenas uma primeira aproximação. Devemos ter uma visão mais complexa e comedida a esse respeito. Lecionava no Baruch College, na Universidade de Rutgers, e na Universidade do Centro do Arkansas, todas instituições públicas. Murray Rothbard estava no corpo docente da Universidade de Nevada, Las Vegas, outra universidade pública. De acordo com a interpretação estrita e limitada do PNA, nem Murray Rothbard nem eu podemos pretender ser libertários. Isso, por si só, parece-me uma refutação dessa teoria.

Durante a década de 1930, os nazistas chegaram a uma cidade judia com a seguinte

\footnotetext{
${ }^{22}$ Se A insistir, o que seria improvável. Ainda mais improvável seria que qualquer tribunal privado de uma agência de proteção desse muito apoio à demanda judicial de A.

${ }^{23}$ ROTHBARD, Murray N. The Ethics of Liberty. New York: New York University Press, 1998. p. 176-78.
} 
proposta-ameaça ${ }^{24}$. Se os judeus, por escolha própria, entregassem para ser executado um membro de sua congregação aos nazistas, estes permitiriam que o resto da cidade sobrevivesse. Caso se recusassem, toda a população da cidade seria morta. Vamos determinar que os nazistas não estejam mentindo. De acordo com o Talmud, o preceito seria "não violem o PNA". Não cooperem com os nazistas de modo, maneira, aspecto ou forma alguma. Em minha opinião, o rabino-chefe deveria entregar a si mesmo ou oferecer aos nazistas qualquer voluntário da cidade para a execução. Se assim fosse, ele teria salvado vidas. Menos direitos teriam sido violados ${ }^{25}$.

Suponhamos que $\mathrm{E}$ dá a $\mathrm{F}$ uma arma para custódia. Então, um dia, E vem até $\mathrm{F}$ como um bêbado furioso, e exige a sua arma de volta, de modo que possa suicidar-se ou matar a pessoa inocente G. Claramente, seria impróprio para $\mathrm{F}$ devolver a E sua pistola, e, caso $\mathrm{F}$ se recusasse, deveria a E algum tipo de compensação (financeira) por manter propriedade de E contra a vontade deste. Isto é, F violou o PNA, se interpretamos o princípio no modo estrito.

Para concluir. A interpretação restritiva do PNA é a tradicional nos círculos libertários. Nessa perspectiva, é sempre um gol de placa favorecer as reduções das alíquotas de tributos (mesmo quando no "lado errado" da curva de Laffer), apoiar a legalização das drogas e opor-se ao alistamento militar obrigatório. $\mathrm{Na}$ compreensão mais ampla do PNA que proponho neste trabalho, tais questões não são, de forma alguma, tão fáceis de analisar.

Existe algum argumento infalível, acachapante e arrasador que possa reconciliar plenamente o libertarianismo deontológico puro em sentido estrito com o utilitarismo amplo (devemos parar aqui com todos os cenários apocalípticos)? Não. Os "marcianos" sempre podem

${ }^{24}$ Como contou-me o amigo e rabino hassídico Lipa Dubrawsky.

25 Postulamos que o mundo termina logo após a decisão ser tomada, de modo a evitar quaisquer possíveis implicações negativas para o futuro. Talvez, os marcianos entrem em cena nesse ponto. Em se tratando de marcianos, nunca se sabe. dizer: "se vocês aderirem a seus princípios libertários, vamos pulverizar toda a Terra." A bifurcação não pode ser superada, ou, ao menos, não vejo maneira de lidar com ela totalmente. Não tenho nenhum golpe nocauteador para derrubá-la. Todavia, existem maneiras melhores e piores de lidar com desafios desse tipo, além do suicídio, da máquina de Coca-Cola e outros casos desta espécie. Uma maneira é com o libertarianismo estrito: não viole o PNA, ponto final. Se você violá-lo de qualquer modo, maneira, aspecto ou forma, nessa medida você não é um libertário. Rejeito essa opção como inferior ao que pode ser caracterizado como a "teoria libertária da punição". Será que esta última é perfeita? Infalível? À prova d'água? Não. Como David Gordon indicou-me, incorremos no mesmo problema do utilitarismo quando confrontado com o sádico. Devemos levar em consideração a utilidade do sádico? E se devemos, o que dizer sobre o monstro utilitarista que, digamos, tem mais prazer em torturar pessoas do que efetivamente as vítimas sofrem com isso? ${ }^{26} \mathrm{~A}$ seguinte resposta: "Bem, nós simplesmente não contamos tal utilidade" clama por outra resposta: "Por que não contar jamais tal utilidade? Qual é a diferença, com base em sua própria teoria"? De maneira similar, podemos perguntar à teoria que estou propondo no presente trabalho: "Afinal, por que punir o 'perpetrador' da violação do PNA que atira contra a máquina de Coca-Cola, ou salva alguém da tentativa de suicídio ou mata algumas pessoas inocentes de modo que os marcianos fiquem longe de nós? Se essa pessoa é realmente um herói, por que puni-lo?" A resposta "Porque ele violou o PNA" não é totalmente convincente, porque, nesse caso, é bom violar o PNA. No entanto, ainda que seja uma resposta imperfeita, penso que isso é bem melhor do que concordar com a noção de que é mau, do ponto de vista libertário, salvar pessoas do suicídio, atirar contra máquinas de Coca-Cola, etc. cos

26 Não objete, prezado leitor, apontando a inadmissibilidade e impossibilidade da utilidade cardinal, e muito menos comparações interpessoais de utilidade. Agora estamos estipulando todas estas medidas. 